\title{
Reading Places and Writing Design
}

\author{
Valerio Morabito
}

Abstract

The narrative of projects, from analysis to the design, has had an extraordinary evolution due to the technological development of digital representations. Rendering, augmented reality, cloud points representation, virtual reality, digital video, and more have invaded the field of design generating images accessible to any customer. Projects of buildings, parks, public spaces, and new cities are easily recognized by these very well realistic images concerning final appearances of them. This exasperated process toward this kind of representations, however, has led to a substantial uniformity of design communications and quality.

The text would like to open a reflection about creative design processes that read contexts to write ideas rather than producing images to see.

Reflecting on the expressive quality of the language of Rupestrian art, which was the first universal language that preceded the invention of words and verbal narrations, the text tries to understand how its universality achieved by signs, codes, and symbols can, somehow, be reused or transformed in new syntaxes and grammars for contemporary representations. And if they can enhance, complite, and integrate digital tools.

Starting with the grammar and syntax of the Rupestrian art, the text focuses on freehand drawings and sketches as fundamental instruments for developing verbal drawings, delineating a different approach to create speaking images for writing contemporary design ideas.

Keywords

verbal drawings, sketches, perception, abstraction, representation.

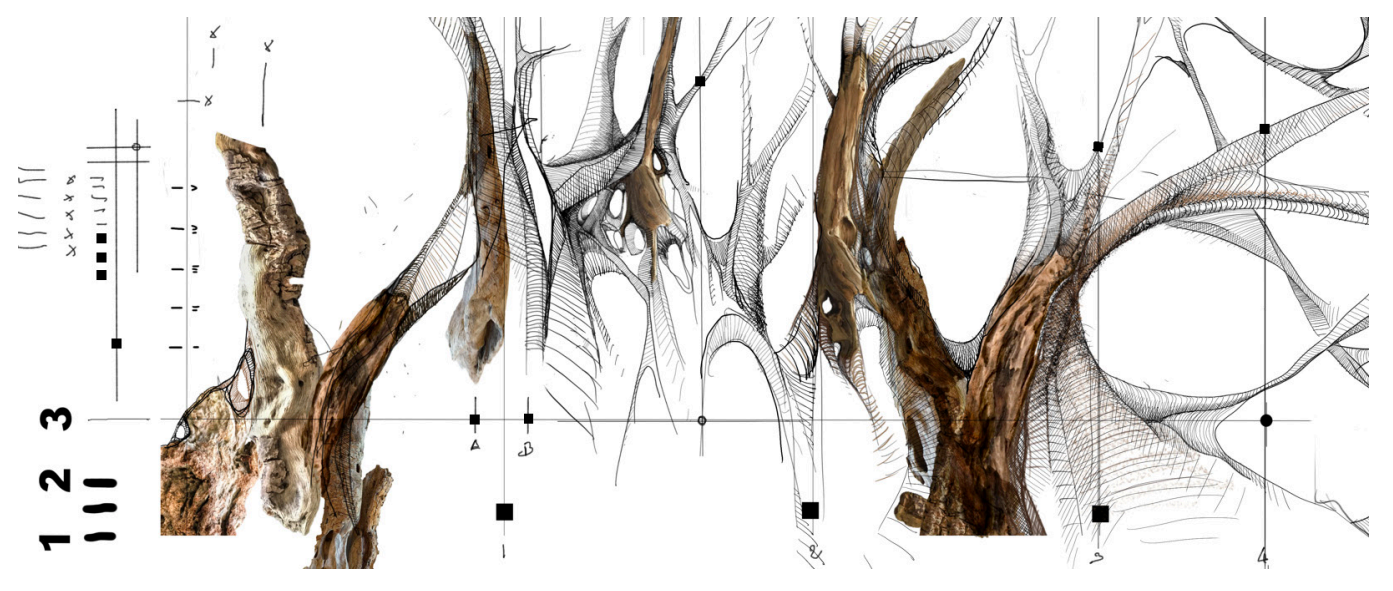




\section{Introduction}

Thinking about landscape as a written text is a relatively common intuitive idea. Less intuitive is how to represent ideas of design in forms of written drawings or verbal drawings [Morabito 2019], at the time when perfect realistic renders and virtual representations are invading our design perception.

The Rupestrian written drawings or verbal drawings were the first human language based on precise grammar, and syntax [Anati 2002] recognized as the first manifestation and representation of landscape [Jellicoe 1975]. Emmanuel Anati [Anati 2002], analyzing over one million pictures, sculptures, and drawings, defines three main elements in the Rupestrian art language: pictograms (bodies of animals or territories) ideograms (signs and marks inside or outside the pictograms to describe the scene,) and psycho-ideograms (abstract transcendental signs and iconic elements far removed from any realistic representation). Being a complex human activity in societies in which survival was of prime importance [Anati 2002], Rupestrian art tells stories, "either profane or sacred, real or mythical facts of special importance" [Clottes 20 I6, p. 5].

The artists of Rupestrian art had to select and memorize specific landscape scenes to be described which are recognized like languages made by words [Lommel 1967]. Finally, they had to find a surface, object, or stone upon which to paint or engrave scenes.

These actions, and more, generated dynamic landscape drawings to read, rather than static images to see [Morabito 2019].

Fig. I. Final Presentation, 2019. Landscape representation course at the Stuart Weitzman School of Design at the University of Pennsylvania (Margarida Mota, student ASLA).

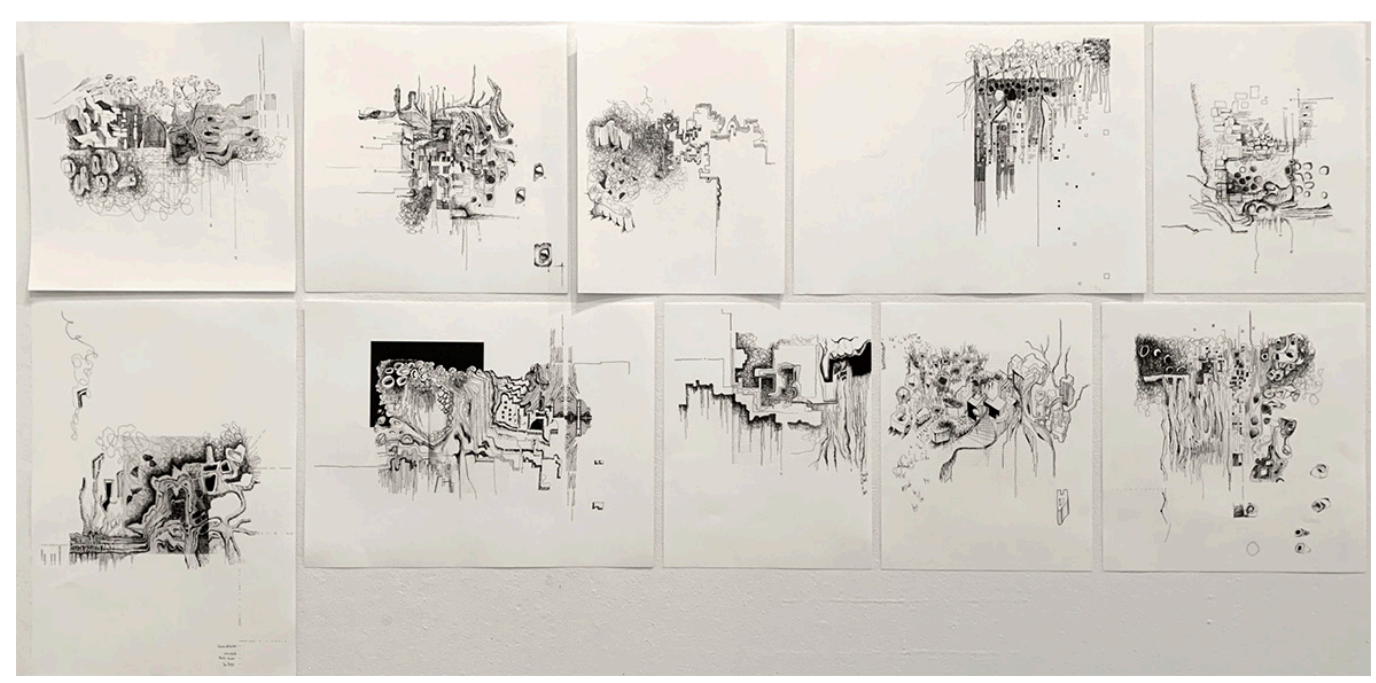

Reading and writing

There are many methodologies and techniques to read and then to represent our contexts and environments. For example, an ecologist is interested in the ecological aspect of the environment, describing it through diagrams of ecological and resilience evolutions. An economist takes into consideration the economic values of lands, buildings, activities, and productions. For an architect or landscape architect, interested in design, environments and contexts are landscapes to be read, selecting and organizing information for an exact narration of their identity. Reading a landscape means to recognize, catalog, and decipher its words, grammar, and syntax, but a text of landscape differs from a text made by words. The landscape combination of elements combined in specific grammar, and syntax generates complex and, many times, contradictory meanings and significance because "different people place emphasis on different aspects" [Bell 1966, p. 6]. Same words, grammars, and 
syntaxes can be read using divers languages; codes, symbols, and traces of landscape might be deciphered differently. When a landscape is read in relationship of a design process, it is not enough to collect roads, buildings, trees, rivers, and infrastructures contained in the landscape. Indeed, it necessary to read it through an 'idea' [Calvino 1988] of landscape. The relationship between the landscape and the designer, the encounter between the genius loci and the genius of designer [Dixon 20/3] creates particular poetic responses that generate ideas of landscape [Dixon 20 I 3].The designer's personal and intimate prose is universalized by the physical and intangible aspects of landscape, inventing understandable languages.

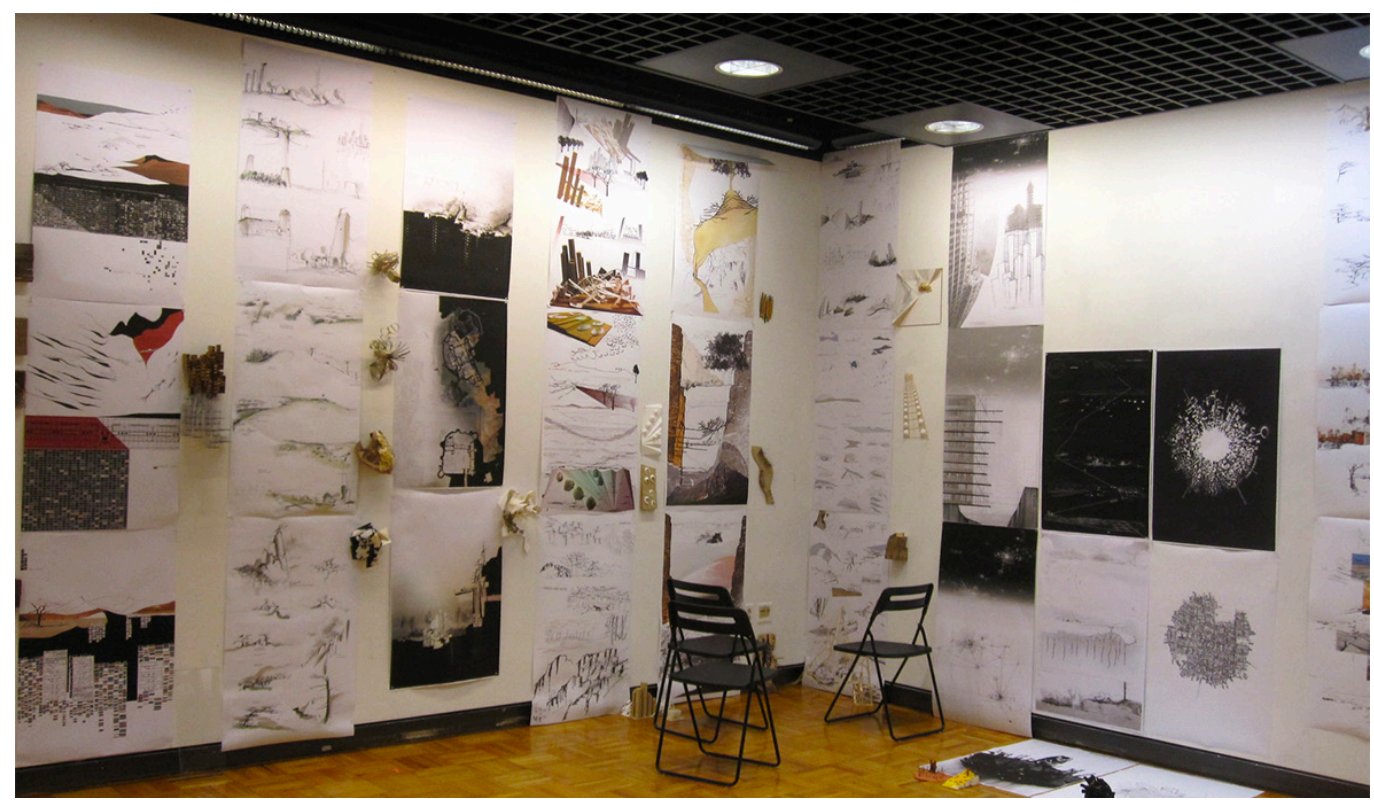

The method of modern abstract art for reading the landscape

An architect or landscape architect can read landscapes using different approaches and methodologies. A particular method is the abstraction of elements, geometries, and morphologies of landscapes [Corner, Hirsch 20 I4], because "the determination of artistic forms depends exclusively on the inner impulses of the subject" [Argan 1990, p. 144].

This methodology of reading landscapes is informed by many artistic movements, such as abstract art, dada, surrealism, and precisionism. Artists like Paul Klee with his rational poetic vision of reality, Ivey Tanguy with his irrational precise landscapes made by formal and informal objects, and Charles Demuth, who meticulously fragments cities, are just a few examples to point out, but the list could be much longer. Paul Klee's work exemplifies how an entire landscape composition may be made by punctuating evident organizational traces rendered in simple forms. His paintings and drawings from his trip to Tunisia [Baumgartner $2014]$ are a crucial milestone in developing this approach. Among the landscapes made of scrolls, grids, and curved-edge polygons, the traces and imperfections are open to many different interpretations. Tanguy invents small or big elements that have distinct meanings and particular languages. Charles Demuth represents fragments of cities that show an intimate domestic perception of our cities.

When Marcel Duchamp decided to compete anonymously for an art competition [I], he wandered around New York City, seeking an object able to represent his idea of art without artists. When he saw a fountain in a fountain shop window, he understood it was the fitting 
object to be used for representing his innovative idea of art; later known as the ready-made artistic theory. For students (and not just for them) in landscape architecture, urban design, and architecture, Duchamp's method of finding objects (traces, symbols, codes) in the city is a creative poetic and artistic method. Going back and forth between scientific and poetic study, it is possible to create a balance between the certainty of science and the unpredictability of intuition, between the accuracy of data and the poetics of imperfections, between the beauty of measures and the aesthetic of beauty (fig. I).
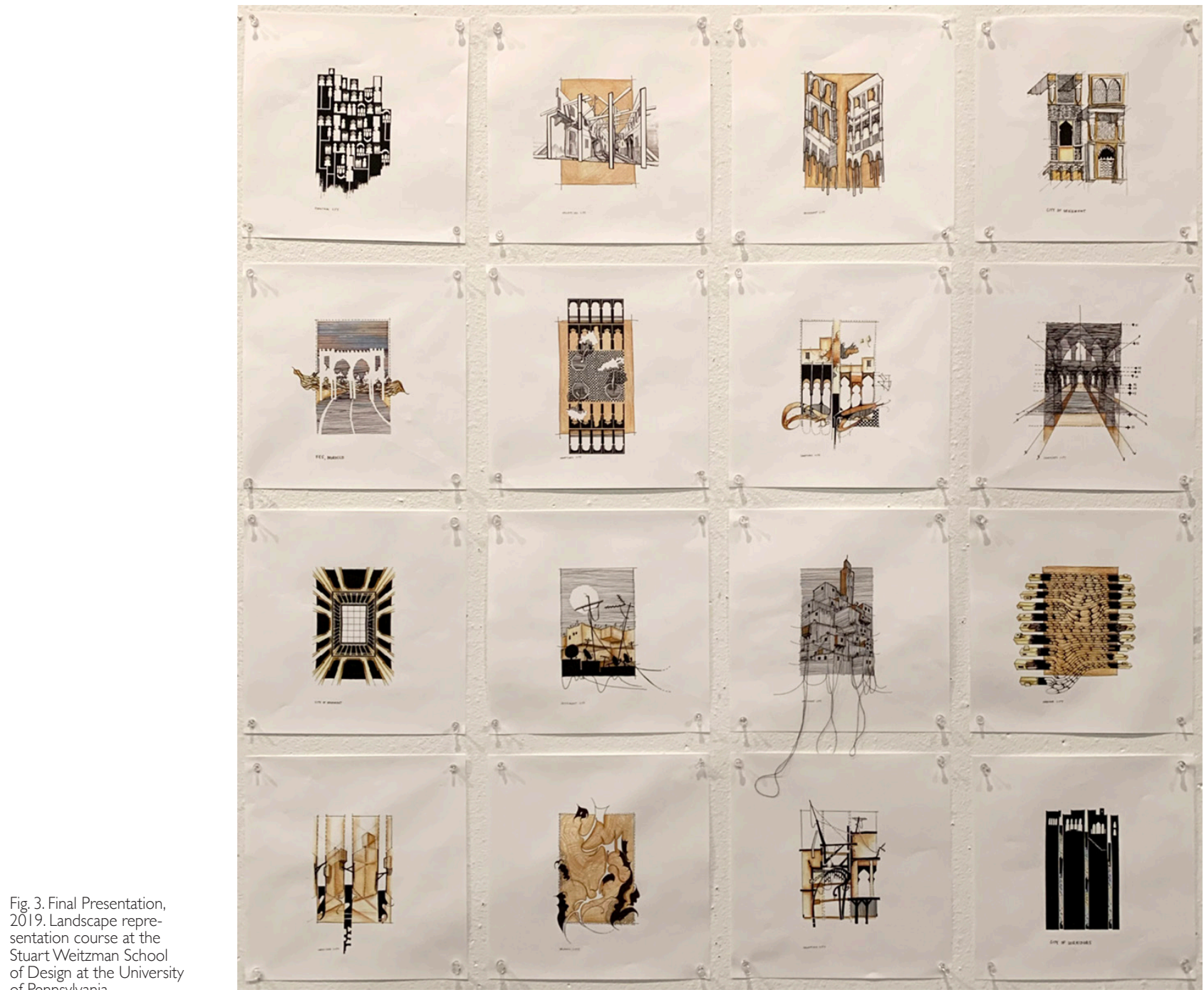

The contemporaneity of hand-writing-drawings

Making sketches and hand drawings is a common way to translate poetic and intuitive readings in written drawings. There are many artists, landscape architects, and architects (especially in the past) that take seriously the use of sketches and hand drawings to represent their idea of creativity. Artists like John Cage, landscape architects like Laurence Halprin, and architects like Louis Kahn -and the list can be much longer- take this inclination to sketch to extreme consequences and results. 
However, in the contemporary design communication hand drawings and sketches seem disappeared, or they play a marginal role. Their ability to communicate ideas appears to be completely inappropriate at a time when everything needs to be controlled at every stage of the design process. Although hand drawings and sketches are crucial at the beginning of the process of creativity for their natural 'imperfection' [Pievani 2019]. It helps to disentangle complex and intricate questions about sites because hand drawings open opportunities rather than closing and finalizing them.

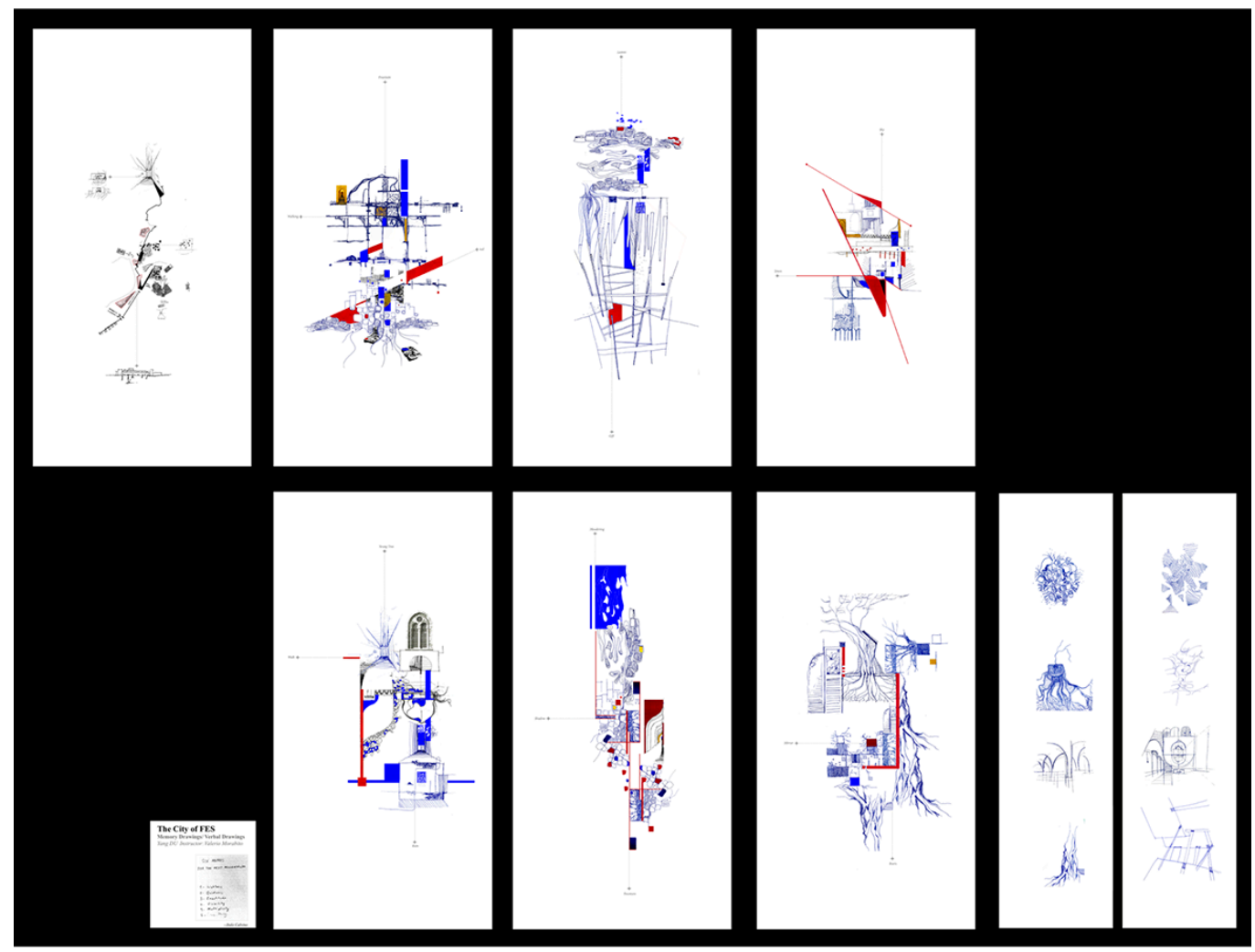

The question is how hand drawings and sketches can have new fundamental contemporary values in a design communication invaded by beautiful virtual and augmented reality. $A$ experiment did at the landscape representation course at the Stuart Weitzman School of Design at the University of Pennsylvania, can contain a few answers to this question (fig. 2). During the classes, photos of different cities that students usually do not know are projected on a screen. Then, students are required to sketch, using a pen, what they see and what they do not see, imagining landscapes that are not in the photos. Their perceptions are regulated by the time to draw, and by the quantity of lines to compose the drawings: sometimes, the image remains projected on the screen long enough, and students can draw what they are looking at with their eyes. Sometimes the image is only projected on the screen for a few seconds, and they have to bring what they remember. Other times students can only use a few lines to represent the projected image; other times, they have a few seconds to draw these images. This exercise improves students' attitudes to use hand and sketches as if they were ordinary everyday gestures, something to do on a restaurant napkin, newspaper, or notebook because they are the first act "of creation, articulated even in the most simple terms". It is "a momentous occasion in a designer's practice" [Hood 2008, p. 57] (fig. 3).

To make hand drawings less artistic and to integrate them at the beginning of design processes, students are required to elaborate them through the use of digital techniques. They 
are free to add pieces of landscapes taken from photos, both from the site or other images; elements considered crucial in their creative process; writings, legends, and symbols that serve to write a drawing rather than to produce images. They have not to create backgrounds with images or colors without any specific meaning and purpose, and to superimpose elements or images randomly. Everything they write must be composed according to grammar and syntax made by pictograms, ideograms, and psycho-ideograms comparable with the Rupestrian art process of writing.

Using this process, even if students have what in Italy is called 'una mano poco felice', literally, 'a little happy hand' -an expression reserved for people who cannot draw well- they can create intelligent lines that are sources for their imagination. The impossibility of drawing correctly forces them to follow imperfections as fundamental elements of their narrative, by which it is possible to perceive and communicate the world differently (fig. 4).

Fig. 5. Mapping Blue City, 2016. Landscape representation course at the Stuart Weitzman School of Design at the University of Pennsylvania (Yuchen Zhao, tudent ASLA).

$$
\text { which it is possible to perceive and communicate the world diferently (fig. } 4 \text { ). }
$$

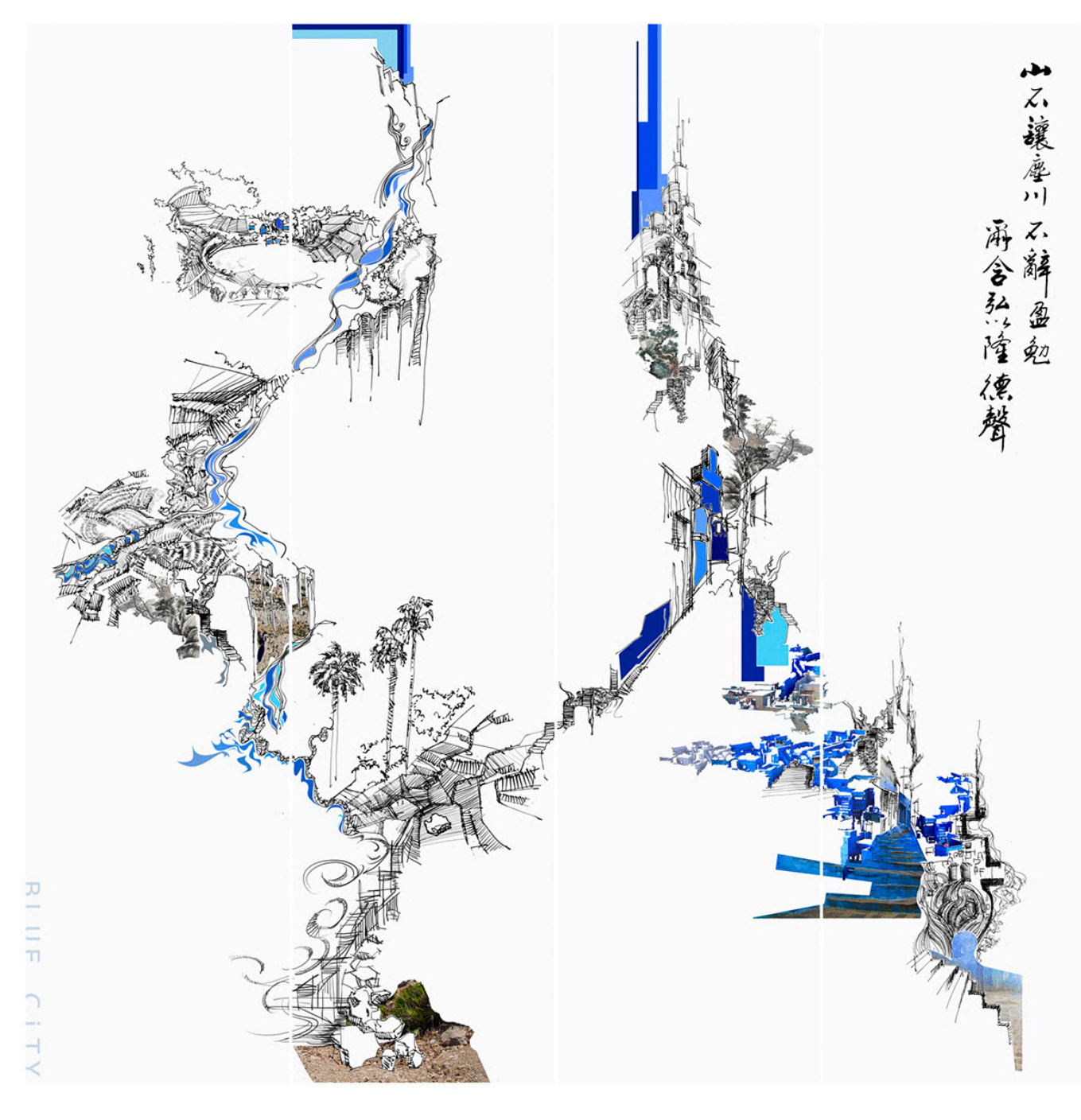

\section{City landscape: a different perception and representation}

Landscapes of cities are usually used to enhance students' design imagination, and creativity. There are many towns that have particular landscape qualities that encourage students to think differently. They are usually small towns or villages characterized by a few elements: a building, a color, a particular urban structure, a culinary tradition, a book, a story, or a legend. 
The city of Chefchaouen, distinguished by an indigo color, is one of them. Lying along the slope of a hillside in the north of Morocco, the city of Chefchaouen is an exciting landscape text to read and reinterpret. Students, by capturing and maintaining the idea of the city, transform its spaces drawing expressive abstract perspectives, plans, and sections, where trees and vines are in contrast/combination with the indigo color, where surfaces of buildings pass from indigo to shades of brown, where streets, steps, doors, and windows are new codes, symbols, and traces. The city is dismantled piece by piece and then reconstructed according to new meanings and forms.

The Mapping Blue City (fig. 5) represents the relationships among the water, morphology, and indigo color of Chefchaouen combined in an emotional and functional narrative language. In the Mapping the desert of Marocco (fig. 6), the idea of the infinite space of the desert of Morocco is designed according to a sequence of imagined villages resembling Chefchaouen. The city of Fes, in Morocco, is another city that creates particular feelings for students. If Chefchaouen is not a typical Arab city, (in fact it was founded by Spanish populations) the city of Fes has the typical Arab city structure. The walls of Riyadh create an urban structure as if it were a complicated rhizome. The windowless walls of the streets widen and narrow, curve and disappear seamlessly. The doors, full of codes and symbols, measure spaces, and make them recognizable. Getting lost in Fes is an extraordinary experience of space that disappears, an emptiness filled with signs and traces to be deciphered. In the drawing The

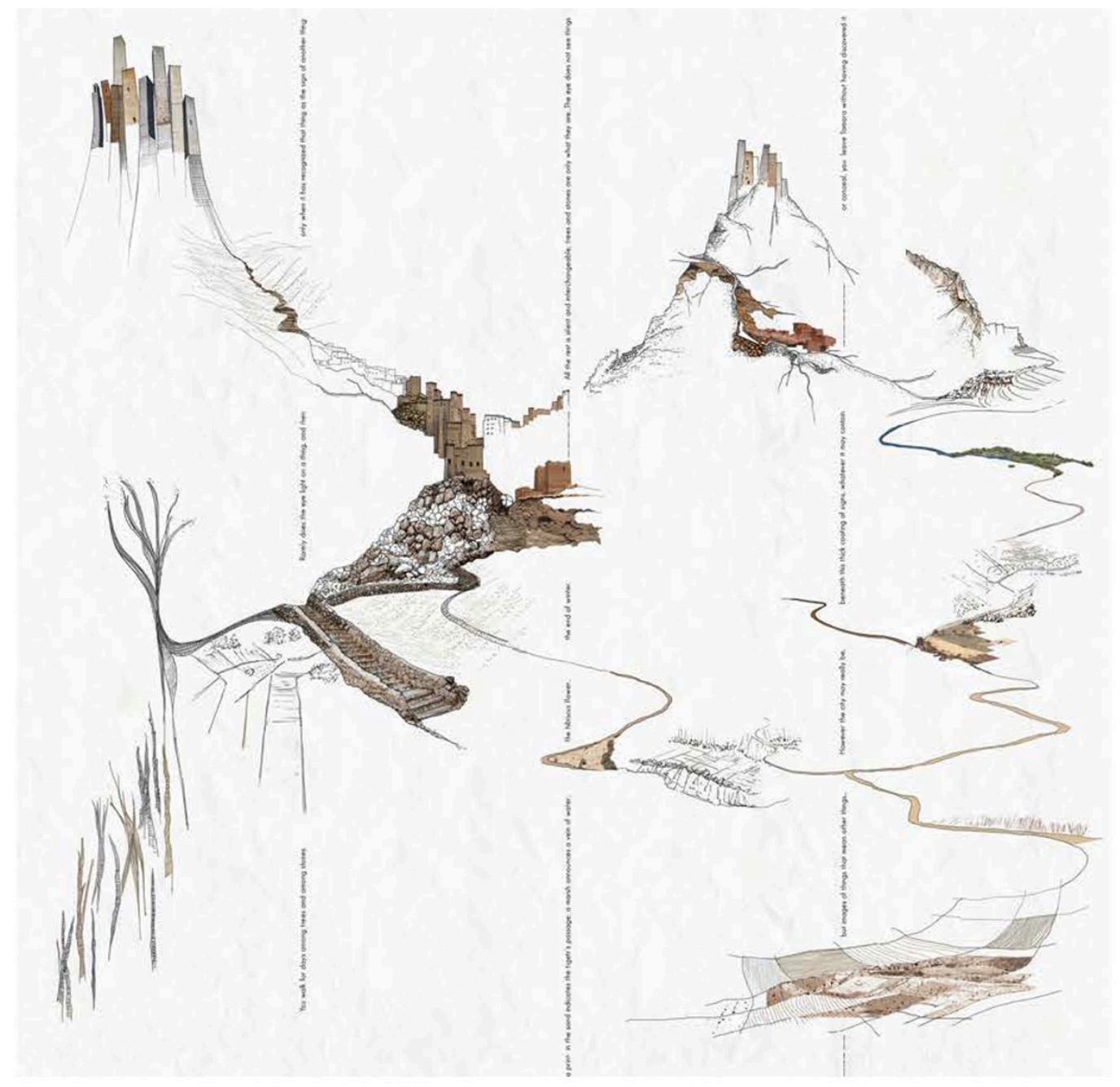




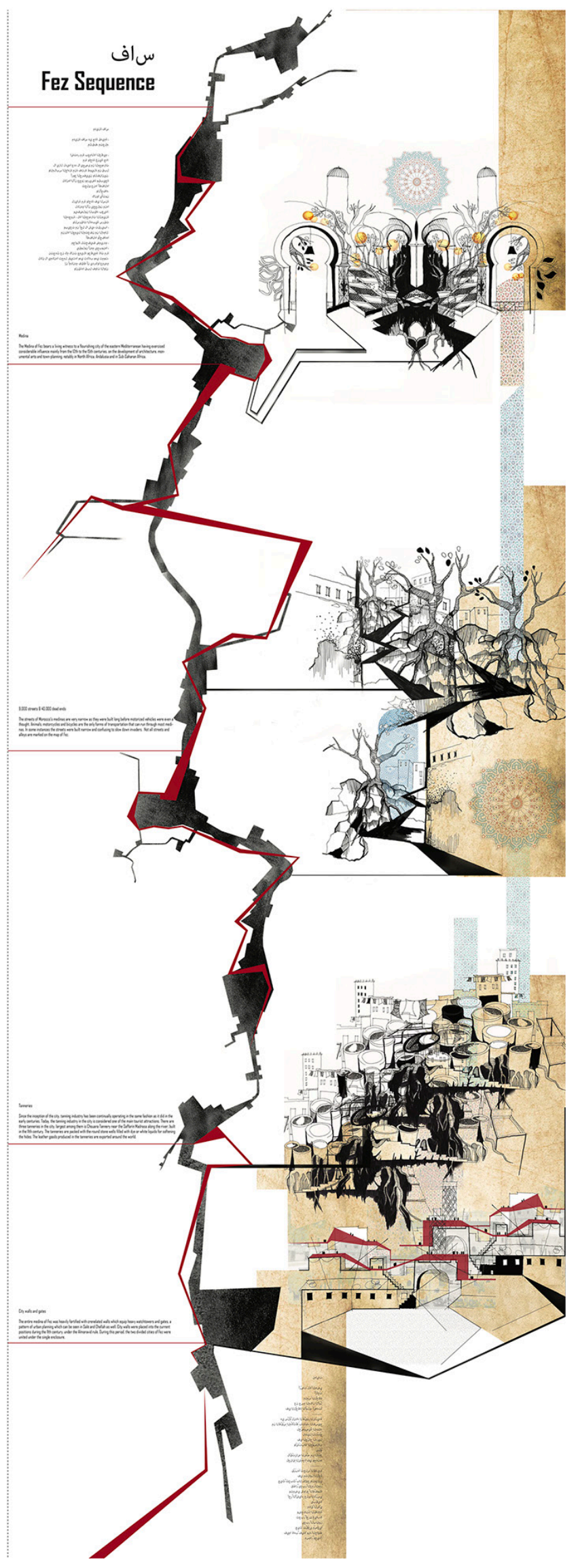



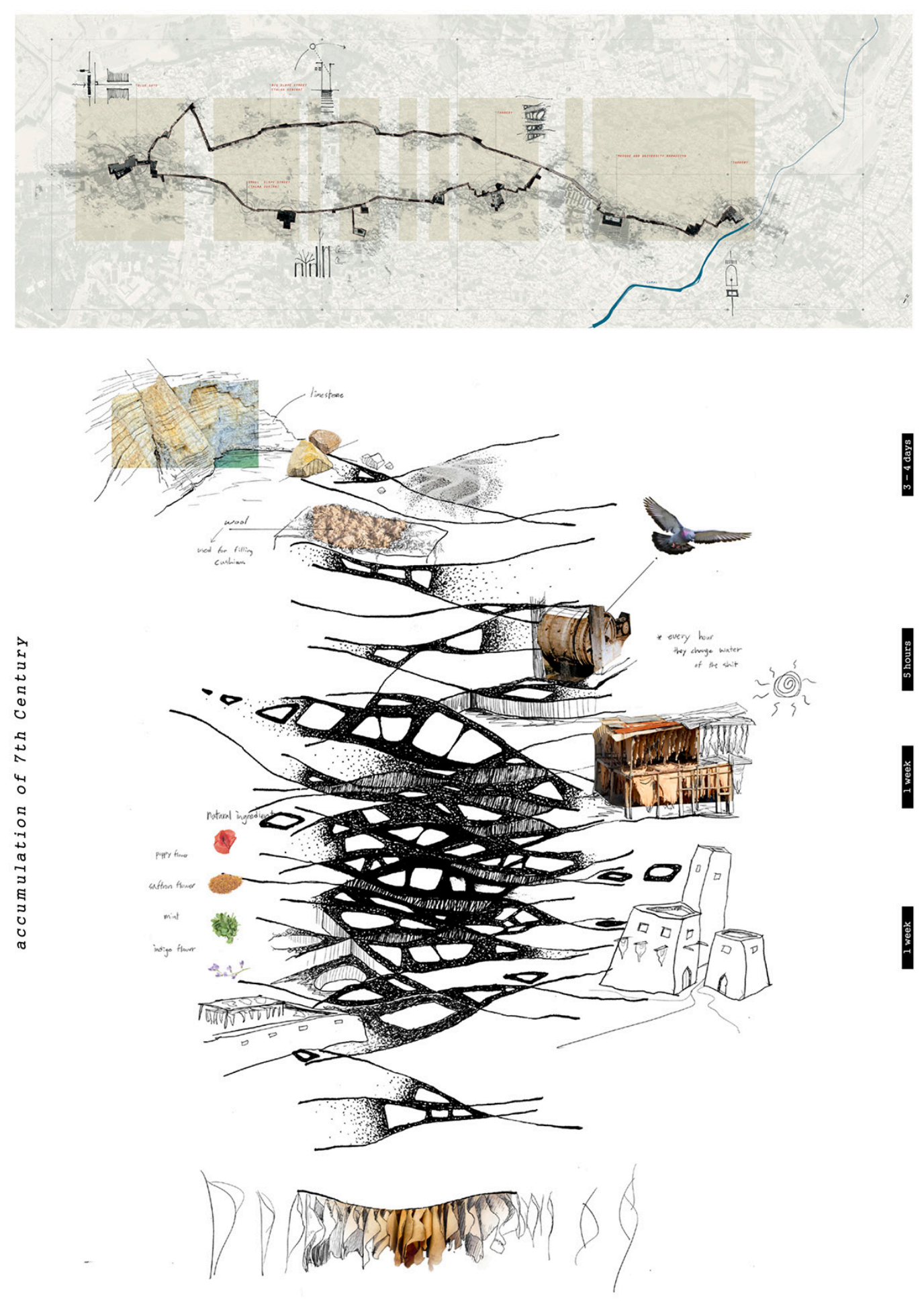
sequence of Fes the city flows seamlessly in a succession of dynamic, cryptic, known and unknown, old and new spaces. The sequence of these spaces represents a way of telling the city without indulging in its beauty but extrapolating its idea (fig. 7). In the drawing Tannery: accumulation of 7 th century, the city of Fes is represented through its tanneries. It's not just a simple representation of real tanneries, but they shrink, compress, and stretch according to a particular idea of design (fig. 8).

The design of the City of San Gimignano is a precious exercise of details and ornaments of the landscape. A combination of photos of physical models, freehand sketches and digital drawings gives back a contemporary city that seeks an active and no longer passive role in imagining new urban structures (fig. 9).

Many times the cities to imagine come from stories, tales, discussions, or only ideas that students develop freely, and the Mapping the City of water is one of these exercises. The city is imagined like geographical connections of a non-real place displaced with precise contour lines and orientations. The arrangement of the points to reach or from which to depart, the direction of the vessels, and other details of the map complete the idea of a dynamic landscape that leads to discovery (fig. 10).

The City of Sabbia results after drawings, memories, ideas developed during the class combined with a series of thoughts, memories, reading experiences of the student's background. The drawing, which starts from memories of the city of Positano, is composed of a plan and a perspective. This city is an extraordinary map of ideas that speaks about traces of creativity and imagination (fig. II).

Through many exercises in imaging and representing both real and unreal cities, students develop their verbal drawings that are written ideas made by harmonious compositions of lines, shapes, and forms rather than images to be seen (fig. 12).

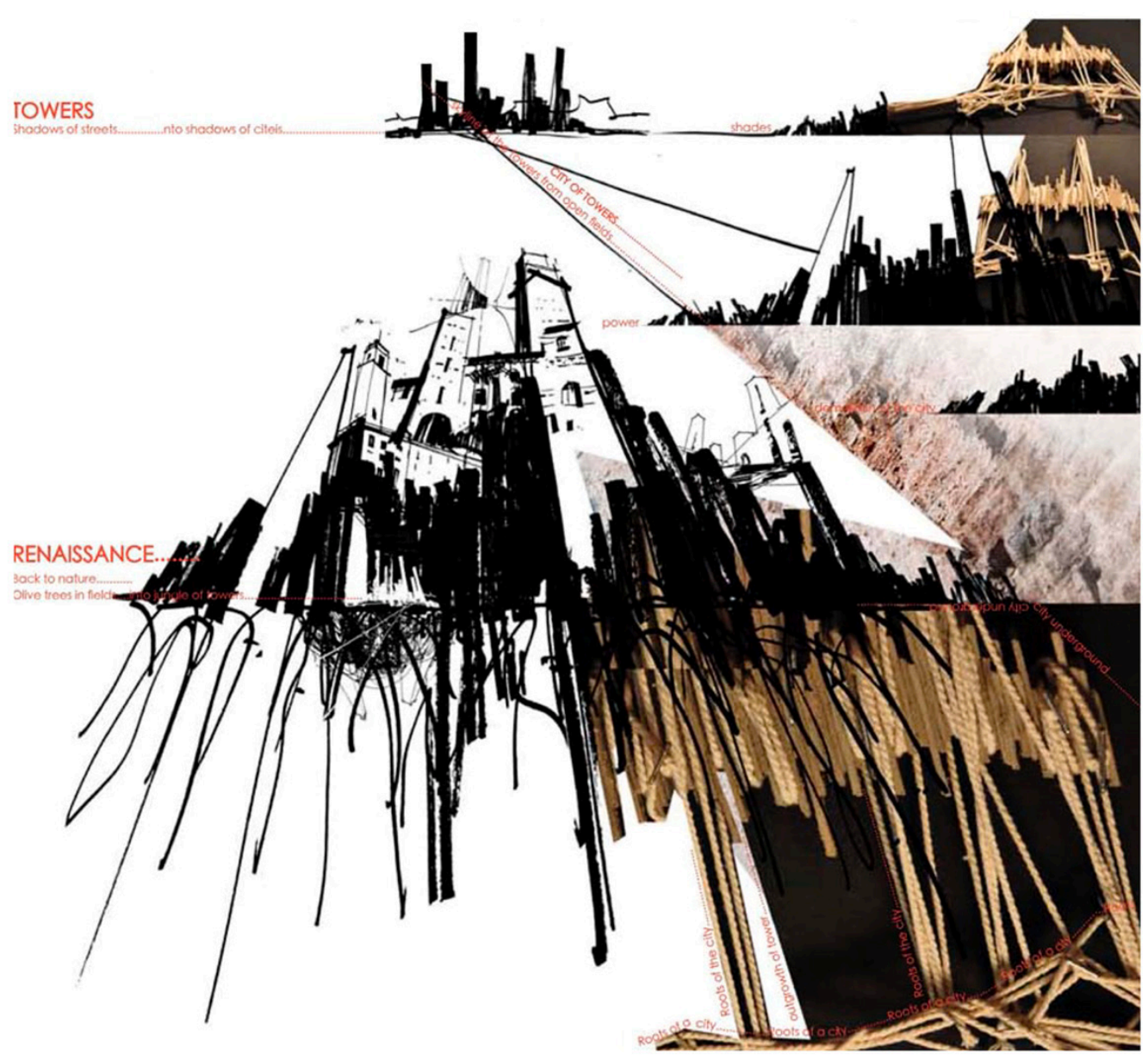




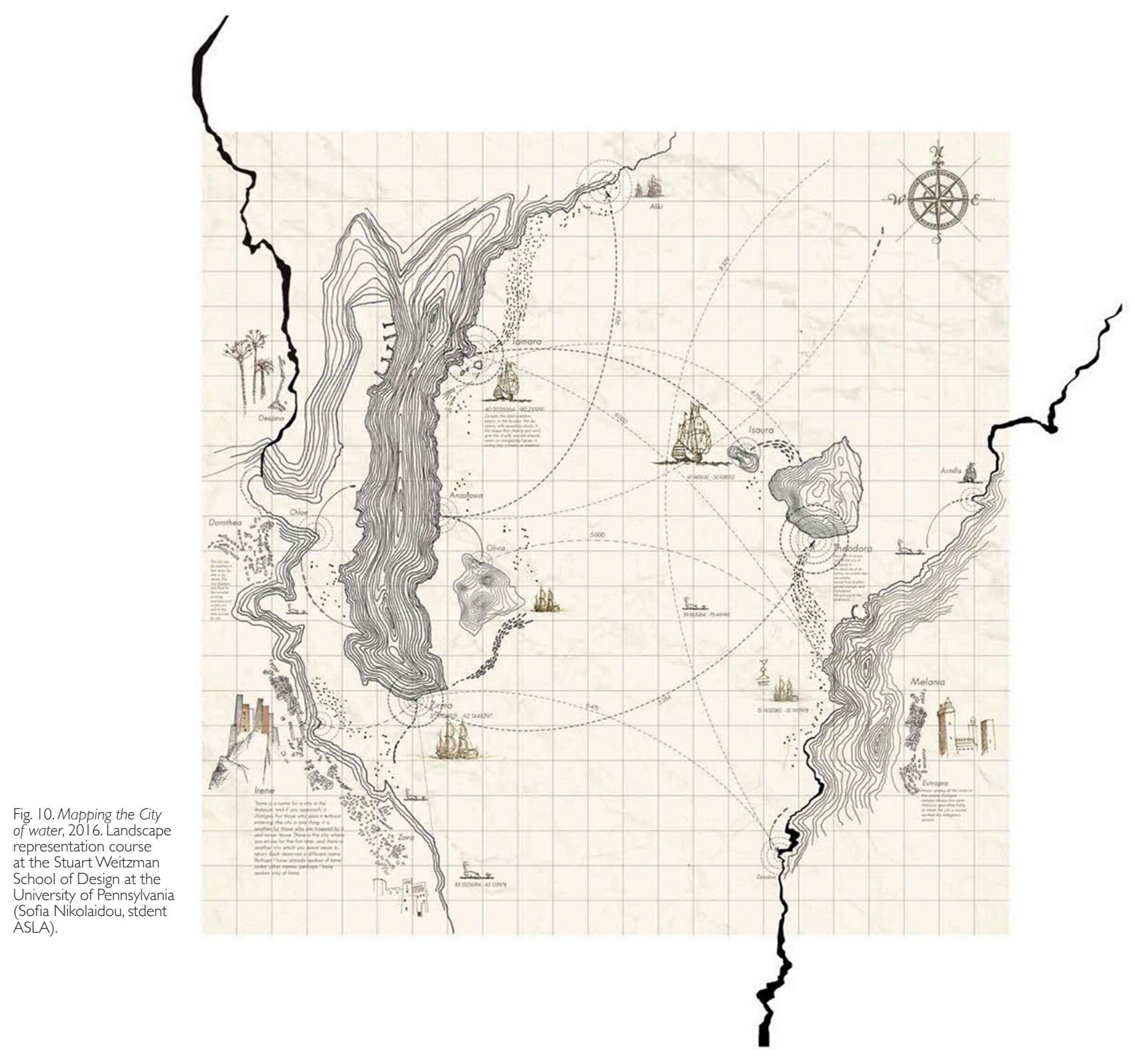


Sabbia, 2015

andscape representation

course at the Stuart We

tzman School of Design

at the University of Penn-

sylvania (Kate Rod
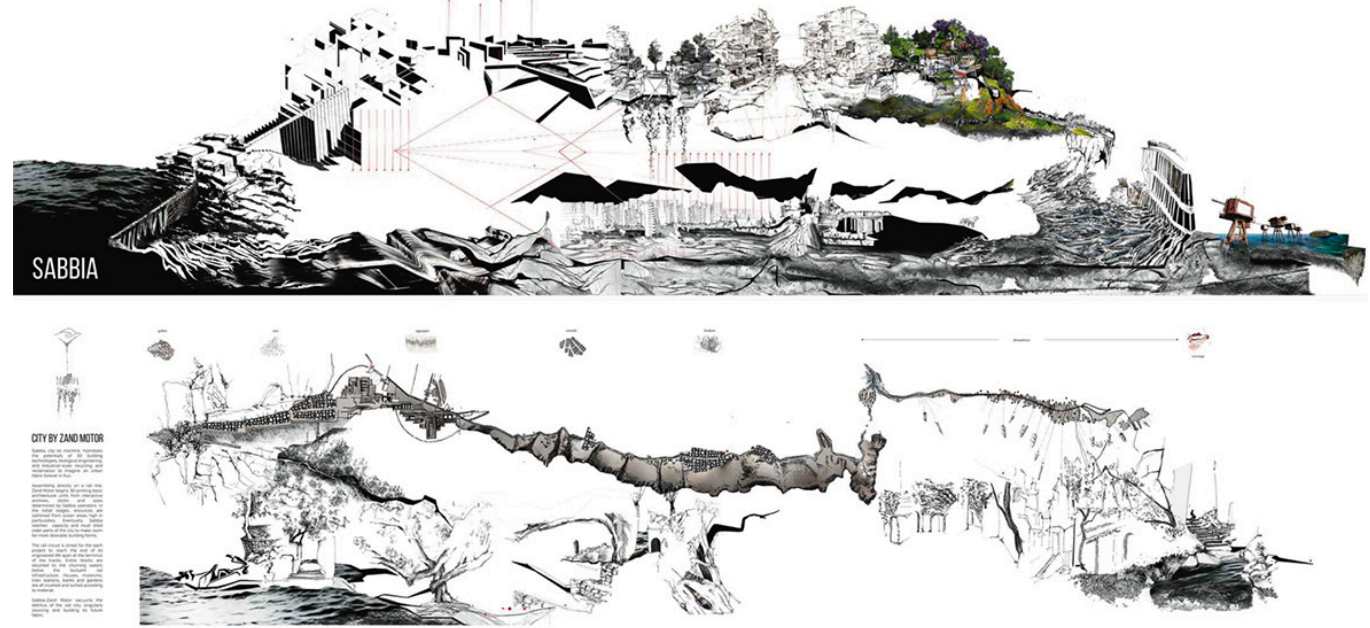

Fig. 12. Thinking about

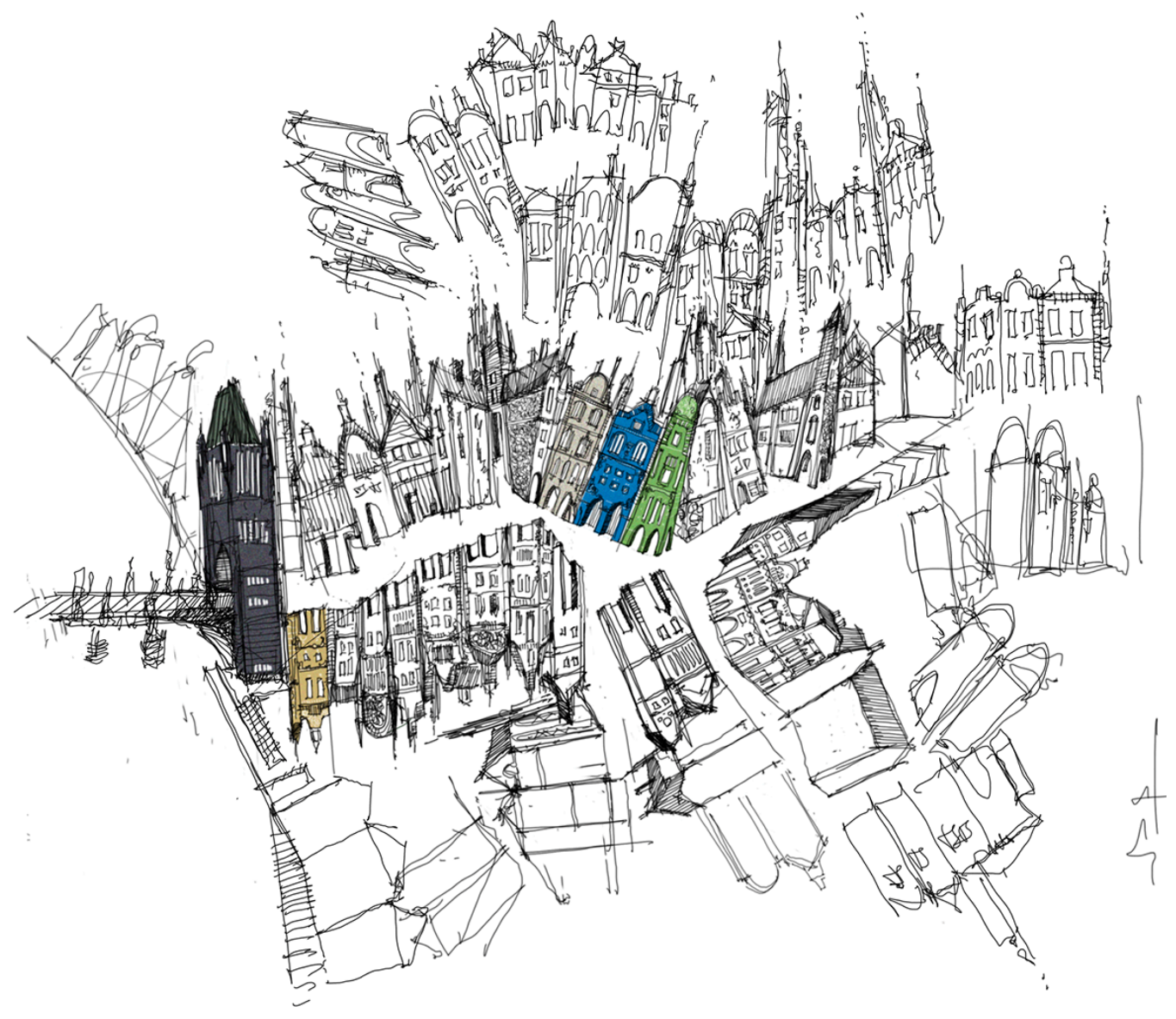




\section{Notes}

$[\mathrm{I}] \mathrm{It}$ is important to remember here that there are discussions about the true origin of the Duchamp fountain. By now it is common thought to indicate the Baroness Elsa von Freytag-Loringhoven as the true author or close collaborator of Duchamp in the elaboration of this ready-made.

\section{References}

Anati Emmanuel (2002). La struttura elementare dell'Arte. Capo del Ponte, Italy: Edizioni Del centro.

Argan Giulio Carlo (1990). L'Arte Moderna. Firenze: Sansoni Editore.

Baumgartner Michael (2014). The journey to Tunisia 19/4. Berlin: Hatje Verlag Gmbh \& Co.

Bell Simon (1966). Elements of Visual Design in the Landscape. London:Tailor and Francis.

Calvino Italo (1988). Six Memos for the next Millennium. Cambridge: Harvard University Press.

Clottes Jean (2016). What is the Paleolithic art? New York: The University of Chicago Press.

Corner James, Hirsch Alison Bick (2014). The Landscape Imagination. New York: Princeton Architectural Press.

Dixon Hunt John (20।3). Sette lezioni sul paesaggio. (Edited and translated by Valerio Morabito). Melfi: Liberia Edizioni.

Hood Walter (2008). Color Fields. In Terib Mark. Representing Landscape Architecture. London, Taylor \& Francis.

Jellicoe Geoffry, Jellicoe Susan (1975). The Landscape of Man. Shaping the environment from prehistory to the present day. London: Thames and Hudson.

Lommel Andreas, et al. (1967). The World of the Early Hunters. London: Evelyn Adams \& Mackay.

Morabito Valerio (2019). Verbal Drawings: mapping landscape ides. In LAF - Landscape Architecture Frontier, n. 4I, Observation and representation.

Pievani Telmo (2019). Imperfezione: una storia naturale. Milano: Raffaello Cortina Editore.

Terib Marc (2008). Representing Landscape Architecture. London:Taylor \& Francis.

\section{Author}

Valerio Morabito, Università Mediterranea di Reggio Calabria, University of Pennsylvania, USA, valerio.morabito@unirc.it

To cite this chapter. Morabito Valerio (2020). Reading places and writing design. In Arena A., Arena M., Brandolino R.G., Colistra D., Ginex G., Mediati D., Nucifora S., Raffa P. (a cura di). Connettere. Un disegno per annodare e tessere. Atti del $42^{\circ}$ Convegno Internazionale dei Docenti delle Discipline della Rappresentazione/Connecting. Drawing for weaving relationships. Proceedings of the 42th International Conference of Representation Disciplines Teachers. Milano: FrancoAngeli, pp. 3577-3589. 